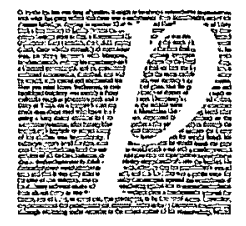

\title{
Sensibilidad victoriana, cuerpos mexicanos: el arte de Adela Breton*
}

\author{
Adriana Méndez
}

\section{Universidad de lowa}

$\mathrm{D}$ esde la época colonial hasta nuestros días, México ha cautivado la imaginación de viajeros extranjeros. Después de la independencia (1825), una amplia gama de viajeros -entre ellos científicos, comerciantes, anticuarios, artistas, filósofos, diplomáticos, arqueólogos y fotógrafos-cruzan el mar hacia la costa de Veracruz por motivos tanto económicos como estéticos.' Si bien los viajeros comerciales se vinculan a una empresa privada, a veces bajo contrato del recién instalado gobierno, ${ }^{2} \mathrm{el}$ artista-viajero va en búsqueda de inspiración en las majestuosas vistas del valle y del sur de México. Decidido a retratar el rostro del paisaje y de sus pueblos, el artista-viajero se somete asimismo a un riguroso proceso de introspección y exploración que resulta en un cambio de óptica, un viaje de autodescubrimiento a la vez que un recorrido por un paisaje extraño. ${ }^{3}$

Junto a la tradición de exploradores científicos y comerciales, las mujeres también cruzaron el Atlántico con la esperanza puesta en el Nuevo Mundo. A diferencia de sus congéneres masculinos, en la mayoría de los casos la travesía por el mar se impulsa por motivos privados más que públicos. Como parte del flujo de viajeras inglesas que inundaron continentes lejanos hacia finales del siglo, varias británicas disfrutaron de

\footnotetext{
Poligrafias IV (2003) 145-158

( $)$ Poligrafias. Revista de Literatura Comparada. División de Estudios de Posgrado, Facultad de Filosofia y Letras, Universidad Nacional Autónoma de México, Ciudad Universitaria, México 04510 DF. Tcl. (525) 622 1835(6). Fax (525) $6221801 ; 6160047 ; 6221826$.
} 
una prolongada estancia en el Caribe, México y América del Sur; aunque vinieran como esposas de un oficial de la marina o de un diplomático, también les motivaba el ánimo de asentar su lugar en el dominio público (Frawley 1994, 21-24). ${ }^{4}$ Fiel a la tradición británica del "viaje de Pénelope," las europeas dejaron huella de su experiencia en tierras ajenas por medio de memorias, cartas, relatos de viajes e ilustraciones (Lawrence 1994). El texto emblemático de este tipo de viajeras es, sin duda, el de Frances Calderón de la Barca, cuyo ameno Life in Mexico-During a Residence of Two Years in That Country (1843) narra las peripecias y aventuras de la esposa del primer cónsul español en un México independiente.

El viaje de Calderón de la Barca se complementa con el de otra viajera inglesa, la artista victoriana Adela Breton (Bath 1849-Barbados 1923). A diferencia de su antepasada y compatriota, Adela Breton no nos deja un legado de escritura, sino un extensísimo y complejo archivo visual compuesto de once cuadernos de acuarelas y dibujos, un álbum fotográfico y una extensa colección de pintura arqueológica, junto con extensas notas en manuscrito sobre las ruinas y templos mayas. ${ }^{5} \mathrm{~A}$ pesar de 10 voluminoso de su producción y de practicar una diversidad de técnicas como la acuarela, el dibujo en lápiz y la fotografia, la obra de Breton no ha sido suficientemente estudiada ni reconocida en toda su amplitud.

Los numerosos viajes de Adela Breton a México, iniciados en 1893, trazan un itinerario de gran complejidad y relieve emotivo: su primera visita al lago de Pátzcuaro la continuó al año siguiente en un arduo recorrido a través de las sierras de Puebla y Oaxaca, viaje que culmina con el encuentro del volcán Iztaccíhuatl. ${ }^{6}$ Entre 1894 y 1895. Breton descubre el Pico de Orizaba y el cofre de Perote; entre 1896 y 1897 recorre los estados de Michoacán, Zacatecas y Guerrero, viajes que siempre parecen culminar en los volcanes como el final de su ruta. Entre 1898 y 1899 , Breton recorre Real del Monte y se despide de México con una última vista del volcán. En 1900 sucede la experiencia de mayor impacto en su vida, la que motiva la etapa más creadora y vital de su producción artística: la primera visita al templo de Chichén Itzá y a las ruinas mayas circundantes como Uxmal y Labná, viaje que representa una frontera o límite en la trayectoria de la artista. En palabras de Graciela Romandía de Cantú, "[e]l entusiasmo que guió su vida entera la llevó a la península de Yucatán, el horizonte más interesante y lejano que ahora vislumbraba" $(1993,56)$. En efecto, el asombro que sintió Breton ante la pirámide de Chichén-Itzá desencadena un retorno recurrente a la zona maya, repetido hasta 1904, fecha en la cual concluye sus impresionantes acuarelas de los recintos sagrados y las ciudades mayas.

Como muchas mujeres victorianas cuyo anhelo de conocimiento las impulsó a descubrir otros mundos, a veces en pares y otras veces como aventureras solitarias (Frawley 1994, 22-23), Breton recorrió el norte y el sur del continente americano, al igual que Europa, Perú y Argentina, captando mediante su arte las particularidades de cada localidad o región que visitaba. La sensibilidad apasionada de esta artista-viajera se desata en México más que en ningún otro sitio; el arte pictórico de Adela Breton muestra el anhelo de captar la poesía del paisaje, el perfil de sus pueblos y las huellas del pasado con una mirada atenta a la curiosidad arqueológica o a la ruina olvidada. ${ }^{7}$ Es 
indudable que el lugar que ocupa Adela Breton dentro de la tradición de la literatura de viajes es el de exploradora visual.

En la historia cultural del México decimonónico, esta función se le ha otorgado canónicamente al pintor alemán Johannes Moritz Rugendas, un díscipulo de Humboldt que viajó a México entre junio de 1831 y marzo de 1834 y quien siguió la misma ruta que su maestro (Diener s/f, 27-36; Holl 1996, 61). Rugendas se adhiere a la estética científica de su precursor, dominada por el imperativo de reproducir en el óleo "la nueva ciencia" propuesta por Humboldt, "la geografía física" basada en "una comprensión totalizadora del mundo" (Diener s/f, 27-36; Holl 1996, 61). Si en Rugendas el impulso científico va a dar como resultado una pintura de tipos y paisajes locales, al igual que una pintura urbana, el arte de Adela Breton va a marcar un sendero diferente.

Si se compara con la sensibilidad de otros viajeros que iniciaron la ruta arqueológica hacia el corazón de la selva yucateca, como el norteamericano John Lloyd Stephens, la mirada de Adela Breton hacia el paisaje y los tipos mexicanos no es la de una viajera "imperial." $\mathrm{El}$ arte de Breton asume, al contrario, una mirada filosófica, introspectiva, dirigida no a la "penetración" del paisaje (término que implica ya una erótica de la mirada) sino, al contrario, a la caricia del terreno, a la envolvente preocupación por sondear el misterio del entorno, revelar su luz; en suma, por reflejar su "esencia." A continuación trazo las relaciones entre Breton y la escuela científica de Humboldt en cuanto a la representación del cuerpo del viajero y después examino el viaje de Breton en términos de la ruta arqueológica emprendida por otros viajeros, contrastando el recato victoriano con la pose de superioridad asumida por Stephens y Catherwood en su espeluznante recorrido por la zona maya. Pór último, paso revista a la representación del cuerpo mexicano en el arte de Adela Breton como sujeto siempre yuxtapuesto a la majestuosidad del paisaje.

\section{I.1. El cuerpo del viajero: el asombro del modelo científico}

Según la historiadora de arte Barbara Maria Stafford, la ciencia dieciochesca establece un método de conocimiento mediante el cual el científico-vidente "desnuda" el objeto para poder estudiarlo mejor (Stafford 1984, 53):

The scientific observer looks at, not over, what he explores. The eye is intently engaged by the aggressive identity of a particular object, with respect to which the beholder takes up a position. (Stafford 1984, 40)

El observador científico mira hacia, no por encima de, lo que explora. El ojo se concentra intensamente en la identidad agresiva de un objeto particular, con respecto al cual el observador adopta una posición. De ahí que el gesto de descubrimiento encarnado en el explorador o viajero implica un cambio de percepción centrado en la mirada que inaugura el procedimiento arqueológico. Los relatos de viaje dieciochescos revelan, por lo tanto, el imperativo de "penetrar" la materia, correspondiente a una "arqueología visual" que pretendia sustraer la sustancia de las partículas naturales, su más íntimo secreto (Stafford 1984, 283-284). 
La sensibilidad cientifica (plasmada en el gran viaje americano de Humboldt) presupone la mirada hacia la fisonomía de la tierra, lo que implica también la esmerada atención hacia la especificidad geográfica de una región o territorio, con el objetivo de develar su "intensa e incontestable personalidad" (Stafford 1984, 46). De ahí que el paisaje devenga no solamente un espacio palpable en el exterior, sino también "el estado de ser o la realidad de una región," lo que constituye, en última instancia, su verdad (Stafford 1984, 57-501). Desde esta perceptiva, la tierra exige ser vista y aprehendida por sí misma, "como una imponente presencia visual" (Stafford 1984, 46).

No hay viaje más emblemático de la curiosidad científica que el de Alejandro von Humboldt; su monumental Voyage aux régions équinocciales du Nouveau Continent (París: 1805-1834) narra la trayectoria de su expedición con el botánico francés Aimé Bonpland por todo lo ancho del continente americano entre 1799 y 1804. Tanto el Essai politique sur le royaume de la Nouvelle Espagne (1811) como el Essai politique sur la île de Cuba (1826) dejan constancia del interés de Humboldt por trazar una geografia local. ${ }^{10}$ Humboldt y Bonpland desembarcan en Acapulco en marzo de 1803 y pronto van rumbo a la capital, con lo que inician un viaje de "redescubrimiento" que va a durar poco más de un año y que comprende el sistemático medir de la zona circundante a la ciudad de México como la exploración de zonas aledañas."

Humboldt investiga también las culturas prehispánicas, desde su curiosidad por la pirámide de Cholula hasta los extensos análisis de códices aztecas y de la piedra del calendario incluidos en Vues de Cordillères et monumens des peuples indigènes de l'Amérique (Iturriaga de la Fuente 1989,118$).{ }^{12}$ Aunque Humboldt no haya visitado personalmente todos los sitios arqueológicos mencionados en este compendio visual, deja cifrada la importancia de determinados sitios con base en el grabado o ilustración hecha por otro artista, como las ilustraciones de las ruinas de Xochicalco y de Mitla o los amenos retratos de tipos indigenas del estado de Michoacán incorporados al relato ilustrado (Holl 1996, 53-55; Humboldt 1816). El mismo eclecticismo - de combinar la pintura paisajística con la indagación y exploración arqueológicas - aflora en el archivo visual de la artista victoriana Adela Breton, con lo que se comprueba la influencia del modelo científico en su arte.

La influencia de Humboldt se palpa en el arte de Breton más que nada en la perspectiva del viajero; específicamente, en la posicionalidad de su cuerpo ante la monumentalidad del paisaje, lo que condiciona, a la vez, la mirada de asombro. Conforme el paradigma del viajero científico, la perceptiva ideal era la vista desde la cúspide, desde la cual se podía observar la gran extensión de tierra que yacía a sus pies, punto de mira desde el cual se establecían comparaciones y contrastes entre terrenos, paisajes, y costas de diferentes regiones del globo. ${ }^{13}$ No obstante, el naturalista-viajero emprende su recorrido desde abajo, desde el valle o llanura que le permite apreciar la altura de la montaña y la majestad del volcán, este último convertido en ícono de lo fugaz y lo sólido conjuntados en la substancia terrenal (Stafford 1984, 105, 215-218). Ejemplo de visión voluntariosa -lo que Barbara Maria Stafford aptamente denomina "willed seeing"(mirar voluntarioso) $(1984,254)$ - la perspectiva de Humboldt se ilustra en Vue de Cajambé, incluida en Vues de Cordillères, donde el cuerpo del 
observador se empequeñece en contraste con la imponente altura de la sierra. $\mathrm{La}$ obligada pose del científico muestra un brazo elevado en señal de asombro, en anticipación de la aventura que necesariamente le sigue al momento de observación detenida: la escalada hacia la cumbre.

En el arte de Breton, correspondiente a una época de transición a la modernidad, se mantiene la misma subordinación del cuerpo humano frente a la magnitud del paisaje. Mientras que Humboldt y sus séquitos se representan a sí mismos (como en Vue de Cajambé, cuyo eje es el trío de viajeros), acentuando así la primacía del espectador, el filtro sensorial que capta el esplendor del paisaje, el cuerpo de Breton desaparece del entorno y pone en su lugar el cuerpo del Otro, los campesinos que pueblan el paisaje con su diminuta estatura. En vez del "ojo penetrante" de Humboldt (Diener 1996, 140), el arte de Breton revela otra mirada hacia el sujeto nacional que podríamos denominar "una mirada del encantamiento."

La acuarela titulada "Jalapa," fechada en enero de 1895 (incluida en el cuaderno Ea 8374, Sketchbook of Watercolours, Drawings, and Notes of México de 1923, perteneciente al Archivo Breton del Museo y Galería de Arte de la Ciudad de Bristol), conjuga la visión artística de Breton, en la cual México aparece como tierra de contrastes, fusión entre lo frío y lo caliente, entre lo alto y lo bajo, las casitas alienadas que descienden hacia la arboleda. El Pico de Orizaba que se asoma nevado en la distancia refleja una imagen recurrente en la literatura de viajes dieciochesca: el pico aislado de la montaña representa, en su majestuosa altura, tanto la solidez monumental de la matẹria como el tipo de mirada que escudriña hasta el fondo de la misma (Stafford $1984,105)$. Ícono de la masa inerte y compacta, la montaña exige una respuesta imaginativa por su dimensión, masa y verticalidad; el antecedente del Pico de Orizaba interpretado por Breton es, sin duda, el ascenso al monte Chimborazo de Humboldt (Stafford 1984, 88), ${ }^{14}$ comparación fundada no sólo por el hecho de tratarse de montañas aisladas, sino también por la forma redondeada del pico.

Siguiendo la pista de Humboldt, Breton evoca el volcán de Jorrullo inmortalizado en Vues des Cordillères, sólo que acentúa la voluminosidad del monte, el aspecto irregular de las cumbres y el juego entre luz y sombra del valle a su alrededor (Ea 11508). En contraste con Humboldt, quien concentra su mirada en el efecto humeante creado por los "hornitos" o conos volcánicos, Breton se detiene en el tamaño de la montaña. Pero, a diferencia del énfasis dieciochesco en la verticalidad y el ascenso, el ojo del espectador se abruma por el impacto de la masa montañosa que se extiende en línea horizontal, resistiéndose al paradigma de altura impuesto por la ciencia de la Ilustración (Stafford 1984, 88). Al seguir y transformar a la vez la perspectiva del viajero científico, Breton transpone la disminuida estatura del cuerpo del viajero al sujeto mexicano, que aparece en contraste con la masa compacta que lo rodea. La respuesta emotiva del espectador recae sobre la figura del jinete solitario quien cabalga en dirección opuesta al monte, como si el liviano trote del caballo contrarrestara la opacidad de la montaña.

De igual forma, la primera visión de Iztaccíhuatl (Ea 8396), a pesar de su precisión científica, no se olvida de incluir la figura humana: el humilde peregrino que camina 
enfrente de la cumbre. La segunda vista (Ea 8397) demuestra la conjunción entre la cumbre y el llano, la fusión entre lo natural y lo humano, al abarcar con la mirada el pueblo de Amecameca apaciblemente asentado al lado de su volcán. Además de volcanes y montes, la pintura de Breton acentúa piedras o promontorios rocosos que se personifican como cuerpos de la materia, residuos de energía universal, como el dibujo en tono marrón del imponente Cerro de los Riscos, cerca de Guadalupe (Ea8260). ${ }^{15}$

En la acuarela trazada en San Andrés Chalchicomula (Ea 8401, 1894) se introduce la entrada al valle de Puebla desde abajo, a través de una ruta rocosa que se abre bajo un acueducto de piedra. ${ }^{16} \mathrm{El}$ atractivo de esta imagen reside en el acueducto que enmarca la vista lejana a manera de un puente natural. Imagen recurrente en el relato de viajes dieciochesco, el puente natural deviene símbolo de la particularidad y originalidad de la materia; en la literatura de viajes a América su paralelo es la litografia del puente sobre el río Iconozo incluida en Vues des Cordillères (Stafford 1984, 80). Sólo que Breton humaniza el paisaje; a lo lejos se vislumbra la sierra; en el centro, una iglesia domina la vista interior del valle; enfrente, como indicando la primacía de una visión femenina, caminan dos anónimas mujeres, ocultas en sus rebozos. Esta visión desde abajo contrasta con el panorama totalizador que se despliega desde la cumbre escalada por los viajeros científicos, ya que la mirada de Breton no sólo conjuga ambas dimensiones, sino que contagia el espacio de lo bajo, el valle, de una presencia humana. ${ }^{17}$ Esta perspectiva se aprecia en la plácida escena de una calle poblana (Ea 8399) en la cual los habitantes aparecen mimetizados con el paisaje y la cúpula de la iglesia a la derecha. Un efecto similar se evoca en la preciosa acuarela que traza la entrada a Jalapa: una suave avenida de barro parece fundirse con los caminantes del pueblo que van o vienen, como la mujer y el niño indígena que marchan al mercado y que ocupan el eje de la composición (Ea8421). ${ }^{18}$ Este afán de conjuntar el mundo natural con el de los afectos humanos era una de las metas de la novela victoriana; de manera análoga, el arte de Breton logra reconciliar el paisaje con la silueta. ${ }^{19} \mathrm{El} \mathrm{mismo}$ efecto se aprecia en la atractiva acuarela que muestra a las lavanderas de San Martín Texmelucan cumpliendo sus labores cotidianas (Ea 8398, 1894), escena que anticipa las imponentes vistas de los volcanes con la sombra azul-grisácea del Iztaccíhuatl al fondo. El contraste entre azules y dorados no solamente enmarca las figuras hieráticas de las mujeres - dibujadas en blanco junto al río, como para sugerir el silencio al que han sido sometidas - sino que resalta también la yuxtaposición entre la altura de la sierra y la paz cotidiana del valle. Una de las más emocionantes acuarelas capta el duelo silencioso en Ocotlán durante el velorio de un niño (Ea 8373), que comunica igualmente el mismo efecto de quietud.

\section{I.2. El cuerpo del viajero: de la carga a la liviandad}

Los itinerarios geográficos e imaginarios de los viajeros decimonónicos conllevaban un reto a las comodidades disfrutadas en Europa y, por lo tanto, un riesgo para la seguridad corporal. En los relatos de viajeros a Hispanoamérica, el desplazamiento hacia zonas desconocidas - sea el interior de la selva, la cima de la montaña o el vórtice de un volcán (como lo hizo el intrépido británico David Thomas Egerton, quien se atrevió a descender al cráter del Popo) - se representa como un reto corporal, una 
ardua empresa que compromete la vida e identidad del viajero, una prueba de su proeza y destreza físicas. ${ }^{20} \mathrm{El}$ ideal del viajero científico era acoplar ser y naturaleza en un todo armónico, unidad que a la vez resultaría en la experiencia de lo sublime y sobrenatural. En aras del conocimiento, se sometía al cuerpo a rigurosas pruebas, como el transporte en vías peligrosas, o a experiencias límite como la enfermedad, la fiebre $o$ el contacto con nativos hostiles. ${ }^{21}$

En la literatura de viajes a México, el monótono rodar del carruaje o el privilegio de dormir en litera condicionan la ruta del viajero (Glantz 1982, 31), así como también el acompañante de la ruta, que puede facilitar o entorpecer la apreciación del terreno, hasta el grado de determinar el alcance final de un agotador trayecto. No hay mejor dramatización del dilema del cuerpo en la literatura de viajes a México que el famoso Incidents of Travel in Central America, Chiapas, and the Yucatán de John Lloyd Stephens, texto que narra el impresionante viaje del empresario a la zona mesoamericana junto con el dibujante y arquitecto inglés Frederick Catherwood. Emprendido en 1841 con la excusa de encontrar un elusivo e inexistente gobierno centroamericano, Stephens pronto revela el verdadero motivo que impulsa su viaje: el descubrimiento de las culturas olvidadas de los mayas. En el relato de Stephens, si bien éste dirige cada etapa del trayecto y declara abiertamente su intención de "penetrar" el mundo maya para explotación comercial - primero quiso comprar las ruinas de Copán y le ofreció al propietario la ridícula suma de $\$ 50$; después intentó trasladar los tesoros perdidos de los mayas a Estados Unidos para luego convertirlos en centro de atracción turística - el éxito de su empresa dependía, en gran medida, de su acompañante (Stephens 1841, I: 126-128). ${ }^{22}$ Aunque Stephens nunca cumple su descabellado proyecto, fueron las románticas reproducciones de estelas y monumentos mayas trazados por la pluma de Catherwood las que garantizaron la enorme difusión y popularidad que el libro gozó en su momento. ${ }^{23}$

Precursor no sólo del antropológo sino también del modelo de explotación comercial, Stephens se enfrenta a la amplia gama de obstáculos que entorpecen la ruta del viajero quien ansía dominar no sólo mediante la vista, sino con todo el cuerpo. A lo largo de Incidents of Travel, los dos exploradores se abren camino entre malezas y jungla con la ayuda de los indígenas de la región. Fue justamente frente a las ruinas de Uxmal que se les imposibilita fijar la imagen del recinto sagrado debido a la enfermedad de Catherwood, quien languidece postrado por una fiebre mortal (Stephens 1841, II: 413, 419). En una escena emblemática del sufrimiento corporal del viajero, Stephens primero rehúsa montar el modo de transporte clásico en Yucatán - un coche cargado en los hombros de los indios, inmortalizado en un famoso grabado del viajero francés Frédérick Waldeck (1838) - por considerarlo denigrante no sólo de su persona, sino también de los sujetos abyectos bajo el peso de su cuerpo. Finalmente, se ve obligado a hacerlo, en gran medida para salvar a su acompañante, el artista Catherwood, de quien dependia para reproducir estéticamente la visión del conjunto. Bajo riesgo de perder a su compañero, Stephens vence sus escrúpulos, justifica la opresión del Otro, cuyo cuerpo queda reducido a bestia de carga, y marca la barrera en- 
tre los indigenas y su Ser individual, literalmente elevado como representante de valores occidentales:

In the great relief we experienced we forgot our former scruples against making beasts of burden of men. They were not troubled with any sense of indignity or abasement, and the weight was not much. (Stephens 1841 , II: 404, 406) ${ }^{24}$

Debido al gran descanso que sentimos descartamos nuestros escrúpulos anteriores de convertir a hombres en bestias de carga. Ellos no se mostraban molestos por ningún sentido de abyección o indignidad, y no era mucho el peso.]

Si bien el texto verbal y visual de Incidents of Travel corresponde a la "retórica de la anticonquista," en el sentido de representar a un "viajero imperial" que posee y domina con la mirada (Pratt 1992, 7), ${ }^{25}$ el vínculo amistoso-aventurero entre Stephens y Catherwood demuestra que el gesto de dominación lo asume el cuerpo del viajero en su totalidad.

Casi medio siglo más tarde que sus precursores, los viajes de Adela Breton representan un modelo diferente, un desplazamiento afectivo que aspira a conocer al Otro de nuestro continente. El afán de conocer al Otro se refleja no sólo en la tecnología del trayecto que la artista británica utilizó durante sus viajes a México, sino, más significativamente, en su compañero de ruta: Pablo Solorio, un indigena originario de Churumuco, estado de Michoacán, a quien Breton contrató en 1893 ó 1894 y quien le sirvió de "fiel acompañante y amigo" durante diez años. ${ }^{26}$ Como el viajero naturalista, el arte de Breton representa un viaje hacia el corazón de la materia, ${ }^{27}$ ciertamente, pero también hacia el corazón del Otro. El modo de transporte preferido por Breton era montar a caballo; no viajaba a manera de un viajero colonial, cargado en hombros de indios, como Catherwood y Stephens encima del coche yucateco. A diferencia de estas imágenes de sometimiento y humillación del nativo, Breton siempre retrata o dibuja a Pablo en primer plano, como en la fotografía del mismo luciendo orgulloso pero sombrio el traje plateado de charro, o las poéticas evocaciones de un Pablo introspectivo, a caballo y de cara al paisaje de Guerrero, o en quietud reflexiva adentro de la penumbra de la choza. ${ }^{28}$ A pesar de estas imágenes idílicas, la correspondencia de Breton da cuenta de que Pablo, como guía y ayudante, le proporcionaba la ayuda indispensable para su supervivencia en el campo. ${ }^{29}$ No obstante la marcada jerarquía entre la extranjera y el nativo, estas fotos traslucen un tipo de relación más compleja que la entablada por el europeo que domina al sujeto subalterno, ya que Breton toma a Pablo Solorio como objeto de inspiración. Graciela Romandia de Cantú opina que la presencia de Pablo "le servía de referencia de la escala humana bajo la fronda de un gran árbol o de pie ante un peñasco redondo" $(1993,38)$, es decir, como modelo del cuerpo mexicano.

Entre Breton y su acompañante se entabla, entonces, una compleja relación de dependencia, respeto y afecto mutuo que a veces se asemeja a un matrimonio célibe, ${ }^{30}$ y otras veces sugiere una ingenua colaboración, como cuando Solorio ayuda al afán coleccionista de Breton y le proporciona artefactos y estatuillas que encontraba en el camino. ${ }^{31}$ No hay imagen más precisa de este viaje alternativo que la famosa fotografía incluida en la contraportada de The Art of Ruins y en el catálogo de la exposición Una 
artista británica en México. Desde la altura de su caballo, ni tan soberbia ni tan impersonal como la cumbre alcanzada por los viajeros científicos, Adela Breton sonríe a través del tiempo, como gesto afirmativo de una relación ambivalente que mediatiza la distancia entre uno y otro, si bien no transgrede los estrechos confines del recato victoriano, ni traspasa las barreras de raza, clase y de género. Pablo también sonríe y aprieta las riendas del caballo en guiño de complicidad, como para advertimos al inicio del viaje que la ruta a seguir es un sendero imaginativo.

\section{La arqueología visual: el México mágico de Adela Breton}

Bajo el volcán y junto a la pirámide, Breton encuentra lo sublime del paisaje y articula una profunda visión artística que incorpora también al Otro que se refleja en su mirada. ${ }^{32}$ La especifidad de la pintura de Breton reside en la manera como su visión interior se ajusta o se construye como analogía pictórica al sentido último del paisaje, a la descodificación de una cultura e historia cuya complejidad e intensidad se convierte en experiencia viva e interiorizada, lo que hace del viaje no sólo un proceso de autoconocimiento, sino también un acercamiento al Otro. En el arte de Breton, el impacto del Nuevo Mundo transforma la "mirada inocente" de pintores y novelistas victorianos y la convierte en una mirada del encantamiento, análoga a la de otras viajeras europeas que recorrieron las mismas regiones.

La "Estatua de una diosa" cerca de Texcoco (Ea 8283b) revela otra faceta del arte de Breton: el empeño en liberar la energía femenina concentrada en el cuerpo abultado de la diosa compuesto de una hilera compacta de piedras, ${ }^{33}$ auténtico "monumento natural." Esta "arqueología natural," dominada por el escrutinio de la vista pero también por la reacción emotiva ante el paisaje, se traslada a las exploraciones del mundo maya que Breton llevó a cabo con tanto éxito y dedicación en la península yucateca. La pintura arqueológica de Breton constituye no sólo una exhaustiva investigación de la cultura maya sino, quizás más significativamente, una nueva práctica del método arqueológico, ya que la artista victoriana entrega su cuerpo y energía no a derribar malezas y jungla, sino a la tarea de reproducir con exactitud de orfebre los monumentos, pinturas y ruinas que seducen su mirada.

En contraste con Stephens y Catherwood, Breton se afana por comprender y rescatar los restos de una cultura, en gesto de amorosa veneración. Breton -quien contrarresta el impulso de Stephens de apropiarse de Copán y Palenque, el cual contamina la investigación arqueológica con las características de una transacción comercial- lucha por conservar la cultura maya en su estado original, como en su casi religiosa tarea de delinear pictóricamente la hermosa serie de cariátides $O$ atlantes colocadas al frente del Templo de los Jaguares en Chichén (Ea8189-xvB; Romandía de Cantú 1993, 125-129). ${ }^{34}$ En el arte de Breton las pirámides y estelas mayas se imbuyen de una luz peculiar; los monumentos parecen "naturalizados" o mimetizados en la selva, en armonía con la naturaleza circundante (Ea8224, Casa de las Monjas, Uxmal). Su suave interpretación va en marcado contraste con las litografias románticas ejecutadas por Catherwood, donde las estelas se erigen en la selva envueltas en un hálito misterioso, casi desprendidas de su entorno natural. Si en Catherwood el 
lánguido sujeto masculino aparece "rarificado" o fuera de su ambiente - sea en su empeño de tajar la profusa arboleda que encubre la codiciada meta de la ruina o en el trato discordante con los nativos de la región- en Breton se elimina la violencia implícita en el modelo de investigación arqueológica representado por Stephens y Catherwood. Mientras que Catherwood cae, como Egerton, en el pozo más profundo en su esfuerzo por descender hasta el fondo de la tierra-ansia teñida de peligros pero nunca colmada-, ${ }^{35}$ Breton se mantiene quieta junto a la pirámide para conectar su visión con la de los antiguos habitantes del lugar. La empatía con el Otro que imbuye el arte de Breton se revela también en retratos que captan una etnia o fisionomía particular, como el ameno cuadro de una doncella totonaca vestida en traje regional (Ea8374) o los rostros hieráticos de las mujeres que se enfilan con su cántaro a la fuente en las fotografias tomadas en Guadalajara (Ea8444). ${ }^{36}$

Rescatar el arte de Adela Breton corrobora la tesis de que las viajeras de la época victoriuna proyectan una historia social alternativa que rebasa tanto los limites del imperio británico como los cánones del discurso imperial (Frawley 1994, 35) ${ }^{37}$ Las inglesas que buscaron otra vida en tierras lejanas han sido clasificadas de acuerdo con tres tipos: las viajeras que observaron el territorio extranjero desde afuera, las que desearon integrarse plenamente a la nueva cultura que las acogía y las que se colocaron cautelosamente en el punto medio sin detener su mirada ni tratar de pertenecer a la sociedad del Nuevo Mundo. A esta tercera categoría para quienes el viaje se convierte en empresa imaginativa, viajeras que sucumben al embrujo de lo extraño y lo desconocido, pertenece el arte de Adela Breton. ${ }^{38}$

*Agradezco la generosa beca de verano de la National Endowment for the Humanities, 2000, que hizo posible la investigación para cstc cusayo. Con gesto de amistad y aprecio, dedico el mismo a Lois Parkinson Zamora, quien me descubrió el universo de Adela Breton. Una versión abreviada de este cnsayo sc presentó cn el "Encucntro: cuerpos y sensibilidades" patrocinado por la Bencmérita Univcrsidad Autónoma dc Pucbla y El Colegio de Michoacán, 27-28 de novicmbrc, 2001. Agradezco a mi amiga y colcga, la Dra. Rosalina Estrada del Instituto de Ciencias Sociales de la BUAP, su amablc invitación a participar en este cvento.

\section{Notas}

${ }^{1}$ Para una rigurosa visión del conjunto de la literatura de viajes a México, véase José Iturriaga de la Fuente (1989).

${ }^{2}$ Véase Margo Glantz (1982) para una amena descripción de los viajeros comerciales al México independiente.

${ }^{3}$ Según Roberto González Echevarría, "the travelogues not only gave an account of the objects found but also of the process by which they were found, that is, the story of the traveler's life as he journeyed in search of the secrets of nature, which of course also turns out to be a voyage of self-discovery" $(1990,104)$. Como espero mostrar, esta búsqueda adapta modalidades diferentes en el caso de una mujer/artista.

${ }^{4}$ Agradezco a mi colega Florence Boos el haberme proporcionado el importante estudio de Frawley. 
${ }^{5}$ Las referencias al archivo Breton en el Museo y Galería de Arte de la Ciudad de Bristol se incorporarán al cuerpo del ensayo.

${ }^{6}$ Agradezco a Sue Giles el haberme proporcionado el itinerario de Breton minuciosamente reconstruido a partir de la serie de dibujos, acuarelas y notas de viaje. Los datos que se encuentran a continuación provienen de esta fuente.

${ }^{7}$ La información autobiográfica proviene de Mary Frech McVicker $(1989,13)$.

${ }^{8}$ El término proviene de Mary Louise Pratt (1992).

${ }^{9}$ Concepto derivado de "mirada filosófica," de Barbara Maria Stafford (1984, 254).

${ }^{10} \mathrm{Al}$ contrario del juicio de Pratt de que ambas son obras caracterizadas por "ahistoricity and the absence of culture" ["una perspectiva ahistórica y carente de contexto cultural"] $(1992,131)$, propongo lo contrario, que están profundamente imbuidas por la presencia de una historia y una cultural local. Para el impacto de Humboldt en Cuba, véase el importante prólogo de Fernando Ortiz a la edición española del Ensayo politico sobre la isla de Cuba, especialmente la sección que detalla la simpatía del alemán por la causa separatista cubana (Humboldt 1960, 84-89). José Miranda (1962) traza el trasfondo del Ensayo político sobre el reino de la Nueva España, la recepción en homenaje a Humboldt que le fue dada por la elite ilustrada de la ciudad de México y la subsecuente difusión de su obra en un contexto nacional.

"Holl traza el itinerario mexicano de Humboldt (1996, 53-61).

12 El editor considera que "el fuerte" de Humboldt era la minería (Iturriaga de la Fuente 1989, 120), mientras que Holl cree que el interés de Humboldt en la cultura mesoamericana era secundario a su interés por la geografia (1996, 55-57). En cambio, Pratt relega la contribución de Vues ... al estudio de las civilizaciones pre-hispánicas (1992, 134).

${ }^{13}$ Para una explicación del "summit-survey" ["vista desde la cumbre"] y del método comparativo de Humboldt, véase Scott Slovic (mayo 1990, 5). La historiadora de arte Barbara Maria Stafford comenta la práctica humboldtiana de "mirar hacia abajo una árida llanura" ["stared down upon an arid plain"] desde las cumbres del monte Chimborazo $(1984,150)$.

${ }^{14}$ La vista del Chimborazo incluida en Vues des Cordillères... se reproduce en la p. 95 de este libro.

${ }^{15}$ Se reproduce en Adela Breton: una artista británica en México (51).

${ }^{16}$ La vista de San Andrés Chalchicomula se reproduce también en Adela Breton: una artista británica en México (66), y en The Art of Ruins (Ea8401, 108), mientras que la imagen del Lago de Pátzcuaro desde el Cerro del Calvario aparece en la p. 100 del primer libro.

${ }^{17}$ Malcom Lowry se remite a esta misma perspectiva en Under the Volcano, novela en la cual los personajes del cónsul, Ivonne y Hugh se desplazan por la legendaria Quauhnahuac con pasos hechizados por el embrujo de los volcanes.

${ }^{18}$ La reproducción de la acuarela se encuentra en Adela Breton: una artista británica (78-79).

${ }^{19}$ A partir de un ejemplo de George Eliot, Levine afirma que " $[t]$ he language and the human form coincide" ["se conjugan el lenguaje y la silueta humana"] $(1977,142)$. 
${ }^{20}$ La imagen de Egerton se reproduce en European Traveler Artists in Nineteenth-Century Mexico.

${ }^{21}$ He basado este análisis en González Echevarría (1990, 107).

${ }^{22}$ Para el episodio posterior, cuando se empeña en adquirir Palenque, véase John Lloyd Stephens (1841, II: 362).

${ }^{23}$ El historiador William Prescott le escribe a Frances Calderón de la Barca que "Stephens' narrative is spirit. But the real value of the work lies in the drawings and simple description of ruins, a perfect assurance of its fidelity" ["El relato de Stephens es todo espiritu. Pero el mérito real de la obra está en los dibujos y en la sencilla descripción de las ruinas, prueba irrefutable de su verosimilitud"] (citado en von Hagen 1950, 62). Años después, el arqueólogo Alfred Maudsley, quien quedó impresionado por los grabados de Catherwood, emprendió la misma ruta que Stephens y Catherwood (Von Hagen 1950, 66).

${ }^{24}$ La ilustración del coche yucateco se toma de Frédérick de Waldeck (1838), litografía titulada "Manière de voyager dans l'Yucatan" (la ortografia de los títulos tal como aparece en la edición príncipe). Agradezco a la Newberry Library de Chicago la reproducción de esta imagen.

${ }^{25}$ La lectura trazada aquí sugiere que el relato de Stephens es mucho más complejo de lo que este modelo supone.

26 "For at least some of her travels in Mexico, Adela Breton was accompanied only by one Indian, who was devoted to her" ["Al menos durante algunos de sus viajes por México, a Adela Breton la acompañó únicamente un indio, quien estaba completamente dedicado a ella"] (Giles 1989, 43). La autora explica a continuación que no se ha podido comprobar ni la edad ni las circunstancias en que Solorio trabó trato con Breton: "His age and other personal details are not known, nor how he came to work for Miss Breton" (44) ["No se sabe ni su edad ni otros detalles personales; tampoco cómo fue que vino a trabajar para la Señorita Breton"] (Romandia de Cantú 1993, 37).

${ }^{27}$ Según Barbara Maria Stafford, "the probing journey into substance [...] emerges as the eighteenth century's distinctive contribution to the venerable genre of travel literature" (1984, 345); ["el viaje de indagación hacia la substancia [...] aflora como la contribución más original del siglo dieciocho al respetado género de la literatura de viajes'].

${ }^{28}$ Esta imagen se encuentra frente a la p. 43 en The Art of Ruins. La foto de Pablo en la Sierra de Guerrero aparece en ese mismo texto (44) y en Adela Breton: una artista británica en México_(39)

${ }^{29}$ Las fotografias de Pablo en el interior de la casa de Chichén y frente a la tienda de campaña en Guerrero atestiguan que Pablo llegó a cumplir múltiples funciones, desde cuidar la casa de Breton hasta procurar y cocinar su alimento en el campo (Giles 1989, 43, 46). Para un amplio comentario acerca de las funciones de Pablo, véase el ensayo de Romandia de Cantú $(1993,37)$.

${ }^{30}$ Por ejemplo, Breton deja que Solorio vaya a visitar a su esposa y mientras tanto suspira porque debido a este motivo no podrá permanecer seis meses más entre las 
ruinas de Chichén. Como explica Giles, la esposa de Pablo se mantiene entre las sombras (1989, 44-45).

${ }^{31}$ Breton le atribuye a Pablo una gran parte de sus hallazgos en tierras mexicanas; a saber, la colección de artefactos que él había reunido (Giles 1989, 45).

${ }^{32}$ De acuerdo con Levine, Ruskin, en un salto imaginativo, "brings together the language of the sublime with that of human society" $(1977,140)$ ["conjuga el lenguaje de lo sublime con el de la sociedad humana"]. El mismo gesto de acoplar ambas dimensiones se evidencia en el arte de Breton.

${ }^{33}$ Reproducida en Adela Breton: una artista británica en México (41).

${ }^{34}$ La cariátide o atlante XV se encuentra representada en The Art of Ruins (79-84).

${ }^{35}$ No hay imagen más dramática de este secreto anhelo masculino que el descenso hacia el pozo yucateco inmortalizado por Fredrick Catherwood en el grabado XX, "Well at Bolonchén" (Catherwood 1844). A mi juicio, este impresionante grabado ilustra "the psychological desire to plumb sublimely dangerous depths" ["el deseo psicológico de caer hacia los bajos más sublimes y peligrosos"] (Stafford 1984, 353).

${ }^{36}$ Incluido también en The Art of Ruins (112).

${ }^{37}$ Propongo con esto ampliar el esquema de Pratt de que todo relato de viaje europeo entronca con la retórica imperial o "la anticonquista."

${ }^{38}$ Frawley establece estas categorias $(1994,35)$.

\section{Obras citadas}

Catherwood, Fredrick. 1844. Views of Ancient Monuments in Central America, Chiapas, and Yucatán. Londres \& Nueva York.

Diener, Pablo. 1996. "Landscape Painting among the Traveler-Artists." European Traveler Artists in Nineteenth-Century Mexico. México: Fomento Cultural Banamex.

s/f. "Rugendas y sus compañeros de viaje." El viajero europeo del siglo XIX. Artes de México 31: 27-36.

Frawley, Maria H. 1994. A Wider Range-Travel Writing by Women in Victorian England. Londres \& Toronto: Associated University Presses.

Giles, Sue. 1989. "'If I Could Have Pablo and the Horses'." The Art of Ruins-Adela Breton and the Temples of Mexico. Ed. Sue Giles \& Jennifer Stewart. Bristol: City of Bristol Museum and Art Gallery. 42-47.

Glantz, Margo. 1982. Viajes a México-Crónicas extranjeras. Tomo I. México: Fondo de Cultura Económica.

González Echevarría, Roberto. 1990. Myth and Archive-A Theory of Latin American Narrative. Cambridge: Cambridge University Press.

Hagen, Victor Wolgang von. 1950. Fredrick Catherwood-Arch. Nueva York: Oxford University Press.

Holl, Frank. 1996. "Alexander von Humboldt's Expedition Through Mexico." European Traveler Artists in Nineteenth-Century Mexico. México: Fomento Cultural Banamex. 
Humboldt, Alexander de. 1816. Vues de Cordillères, et monuments des peuples indigènes de l'Amérique. Vol. II. Paris: Librairie Grecque-Latine-Allemande.

- 1960 . Ensayo politico sobre la isla de Cuba. Pról. de Fernando Ortiz. La Habana: Publicaciones del Archivo Nacional.

Iturriaga de la Fuente, José. 1989. Anecdotario de viajeros extranjeros en México. siglos $X V I-X X .4$ tomos. México: Fondo de Cultura Económica.

Lawrence, Karen. 1994. Penelope Voyages. Women and Travel in the British Literary Tradition. Ithaca \& Londres: Cornell University Press.

Levine, George. 1977. "High and Low: Ruskin and the Novelists." Nature and the Victorian Imagination. Ed. U. C. Knoepflmacher \& G. B. Tennyson. Berkeley: University of California Press.

McVicker, Mary Frech. 1989. "From Parlours to Pyramids." The Art of Ruins-Adela Breton and the Temples of Mexico. Ed. Sue Giles \& Jennifer Stewart. Bristol: City of Bristol Museum and Art Gallery.

Miranda, José. 1962. Humboldt y México. México: UNAM.

Pratt, Mary Louise. 1992. Imperial Eyes-Travel Writing and Transculturation. Londres: Routledge.

Romandía de Cantú, Graciela. 1993. "Adela Breton (1849-1923)." Adela Breton: una artista británica en México (1894-1908). Ed. Mario de la Torre. México: Smurfit Cartón \& Papel.

Slovic, Scott. Mayo de 1990. "Alexander von Humboldt's Comparative Method of Landscape Description." Publication of the Society for Literature and Science 5.

Stafford, Barbara Maria. 1984. Voyage into Substance-Art, Science, Nature, and the Illustrated Travel Account, 1760-1840. Cambridge, Massachusetts \& Londres, Inglaterra: MIT Press.

Stephens, John Lloyd. 1841. Incidents of Travel in Central America, Chiapas, and the Yucatán. 2 tomos. Nueva York: Harper \& Brothers.

Waldeck, Frédérick de. 1838. Voyage pittoresque et archéologique dans la provence d'Yucatan (Amérique Centrale), pendant les années 1834 et 1836. París: Bellizard Dufour et $\mathrm{Co}$, editeurs. 